\title{
Experimental and Numerical Investigation of Combined Sensible/Latent Thermal Energy Storage for High-Temperature Applications
}

\author{
Lukas Geissbühlera, Simone Zavattonib, Maurizio Barbatob, Giw Zanganehc, Andreas Haselbacher ${ }^{\star a}$, \\ and Aldo Steinfeld ${ }^{a}$
}

\begin{abstract}
Combined sensible/latent heat storage allows the heat-transfer fluid outflow temperature during discharging to be stabilized. A lab-scale combined storage consisting of a packed bed of rocks and steel-encapsulated $\mathrm{AlSi}_{12}$ was investigated experimentally and numerically. Due to the small tank-to-particle diameter ratio of the lab-scale storage, void-fraction variations were not negligible, leading to channeling effects that cannot be resolved in 1D heat-transfer models. The void-fraction variations and channeling effects can be resolved in $2 \mathrm{D}$ models of the flow and heat transfer in the storage. The resulting so-called bypass fraction extracted from the 2D model was used in the 1D model and led to good agreement with experimental measurements.
\end{abstract}

Keywords: Packed bed · Phase change material · Simulation · Thermal energy storage $\cdot$ Thermocline

\section{Introduction}

The fluctuating nature of intermittent renewable energy sources such as wind and solar requires short- and long-term energy storage to guarantee the power supply. At present, pumped hydro storage (PHS) is the main option for short-term large-scale storage. Market conditions threaten the economic viability of PHS, however. Compressed air energy storage (CAES) is an alternative technology that has been proven at industrial scale. ${ }^{[1]} \mathrm{Be}$ cause CAES plants waste the heat generated during compression, it must be resupplied prior to expansion, leading to cycle efficiencies of about 40-55\%. In advanced adiabatic compressed air energy storage

\footnotetext{
${ }^{*}$ Correspondence: Dr. A. Haselbacher ${ }^{a}$ aDepartment of Mechanical and Process Engineering ETH Zurich

$\mathrm{CH}-8092$ Zurich, Switzerland

bepartment of Innovative Technologies SUPSI, CH-6928 Manno, Switzerland 'Airlight Energy Manufacturing SA

Via Industria 10, CH-6710 Biasca, Switzerland

E-mail: haselbac@ethz.ch
}

(AA-CAES), the heat produced during compression is stored in a thermal energy storage (TES), resulting in projected cycle efficiencies of 70-75\%, which are comparable to PHS's cycle efficiencies. ${ }^{[2]}$ Advantages of AA-CAES compared to PHS are lower estimated capital costs ${ }^{[3]}$ and smaller land requirements. For these reasons, AACAES is potentially an attractive alternative to PHS for Switzerland. Because the high efficiencies of AA-CAES plants are due to the integration of a TES for temperatures of up to $650{ }^{\circ} \mathrm{C}$, this study is focused on the experimental and numerical investigation of TES for high-temperature applications. The results presented are relevant as well to waste heat recovery in industrial processes and concentrated solar power plants.

Thermocline TES represents an efficient and cost-effective way of storing thermal energy. ${ }^{[4]}$ In prior work, a packed bed of rocks as sensible heat storage material and air as heat transfer fluid (HTF) was experimentally shown to yield $95 \%$ overall (charging-discharging) efficiency.[5-7] A drawback of thermocline TES is the decreasing HTF outflow temperature during discharging, which can reduce the cycle efficiency of AA-CAES. This drop can be reduced by oversizing the storage or increasing its height-to-diameter ratio at the expense of higher pressure drops ${ }^{[7]}$ and/or increasing material costs. Another way of avoiding the temperature drop is through latent TES based on phase-change materials (PCM). Because the phase change occurs at constant temperature, latent TES can, in principle, stabilize the HTF outflow temperature during discharging. Among a large number of potential PCMs, metals are attractive because they offer high heats of fusion and high thermal conductivities. ${ }^{[8]}$ However, intermetallic layers can form between the encapsulation and the PCM, impacting their performance. ${ }^{9]}$ Another drawback of PCMs is that they are expensive compared to sensible heat storage materials. For these reasons, our interest has centered on combined sensible/latent TES with the twofold aim of stabilizing the HTF outflow temperature during discharging compared to sensible-only TES and reducing costs compared to latent-only TES. The combined storage concept was investigated experimentally and numerically at the laboratory scale in previous work. ${ }^{[10-14]}$

For the numerical analysis of TES, 1D models are often used, especially for parametric studies, because the computational cost is much lower than for 2D or 3D models. The simplification to $1 \mathrm{D}$ can be justified if the tank-to-particle-diameter ratio is large, which means that radial gradients are small over the entire cross section except near a small annular region close to the storage walls. In that region, where the length scales of the flow and heat transfer are comparable to the particle diameter, 1D models are not valid. This means that 1D models are more accurate for large-scale than laboratory-scale TES. Therefore, the objectives of this article are: (i) to validate a 1D model of a lab-scale combined sensible/latent heat storage and (ii) to compare $1 \mathrm{D}$ and 2D simulations of that storage. 


\section{Modelling}

\subsection{D Model}

The 1D heat-transfer model ${ }^{[14,15]}$ is formulated separately for the sensible and latent heat sections and the storage structure with the insulation. Fluid, solid, and molten phases are considered and convective, conductive, and radiative heat transfer mechanisms are included. The description below assumes that the PCM is encapsulated in tubes and is restricted for brevity; a more detailed description can be found in refs $[14,15]$. Time integration is performed implicitly and spatial derivatives are approximated with second-order accuracy. The enthalpy method ${ }^{[16]}$ is used to solve the equations of the PCM.

\subsubsection{Sensible Heat Section}

The energy conservation equations for the fluid and solid phases are given by Eqns (1) and (2), where the symbols are defined in the nomenclature. Temperature-dependent rock and air properties are implemented and are taken from refs $[6,13,17]$. The volumetric heat-transfer coefficient $h_{\mathrm{v} \text {,rocks }}$ is determined from Eqn. (3) for the convective heat-transfer coefficient per unit area $h_{\text {rocks }}{ }^{[18]}$ with $h_{\mathrm{v}, \text { rocks }}=a_{\mathrm{s}} h_{\text {rocks }}$ and $a_{\mathrm{s}}=6 \phi_{s} / d_{p}$. The lateral wall convective heat-transfer coefficient $h_{\mathrm{w} \text { onv }}$ is taken from ref. [19] and the conductive-radiative wall heattransfer coefficient $h_{\text {wcond-rad }}$ is taken from ref. [20]. The effective axial conductivity $k_{\text {eff }}$ is calculated according to ref. [21]. The term $q_{\text {interfacerad }}$ represents the radiative heat transfer between the last row of tubes and the top of the packed bed of rocks. Because of the small value of the tank-to-particlediameter ratio, a bypass fraction of $10 \%$ was used in the sensible heat section. This value was obtained from simulations with the $2 \mathrm{D}$ model described below.

\subsubsection{Latent Heat Section}

The energy conservation equations for the fluid and the encapsulation are given in Eqns (4) and (5).

A volumetric air-to-tube heat-transfer coefficient $h_{\mathrm{v}, \mathrm{enc}}$ is used to compute $q_{\text {enc, }}$ and is calculated from a correlation (Eqn. (6)) for the convective heat-transfer coefficient per unit area $h_{\text {enc, }}{ }^{[18]}$ where $h_{\mathrm{venc}}=$ $a_{\text {enc }} h_{\text {enc }}$ and $a_{\text {enc }}=103.45, C_{\text {row }}=0.95, P r_{\mathrm{g}}$ is the gas Prandtl number evaluated at the temperature of the gas, $P r$ is the gas Prandtl number evaluated at the temperature of the solid, and $R e_{\text {max }}$ is based on the maximum interstitial velocity $u_{\max }=S_{\mathrm{t}} u_{0} /$ $\left(S_{\mathrm{t}}-d_{\text {tubes }}\right)$. The term $q_{\text {top.rad }}$ accounts for the radiative exchange between the perforated plate (Fig. 1) and the topmost row of tubes. An energy conservation equation (Eqn. (7)) is solved for each row of encapsulated PCM.
Further details of the model of the latent heat section are available in refs $[14,15]$.

\subsubsection{Storage Wall and Insulation}

The radial and axial temperature distribution in the storage wall and the insulation is determined from Eqn. (8), where $q_{\mathrm{b}}$ represents the heat transfer at the boundaries of the wall and the insulation. At the inner boundary, convective heat transfer to the heat transfer fluid and conductive-radiative heat transfer to the packed bed are accounted for, see the last terms in Eqns. (1), (2), and (5). Free convection heat transfer is assumed at the outer boundary. ${ }^{[17]}$ At the height of the topmost tube row, measured insulation temperatures in each material are imposed as boundary conditions.

\subsection{D Model}

The primary purpose of the $2 \mathrm{D}$ model is to quantify channeling, i.e. the radial variations in the flow and heat transfer due to variations of the void fraction. As stated in the introduction, these variations are important because the tank-to-particlediameter ratio for the lab-scale storage is small. To reduce the computational cost, the 2D model is based on the assumption of axisymmetry of the flow and heat transfer in the storage. The model solves the mass, momentum, and energy conservation and turbulence transport equations using ANSYS Fluent 15.0. Turbulence effects are accounted for with the realizable $k-\varepsilon$ model ${ }^{[23]}$ with enhanced wall treatment. ${ }^{[24]}$ Grid-independent results were obtained with 360'000 quadrilateral cells. The packed bed and the tube rows are modelled using the porous media approach. ${ }^{[25]}$ As in the 1D model, the solid and fluid phases are assumed to be in thermal non-equilibrium. The solid-to-fluid heat-transfer coefficient is computed with Eqns. (3) and (6) for the packed bed and the tube bundle, respectively. Air is assumed to be an ideal gas

$$
\left(1-\phi_{\mathrm{s}}\right) \frac{\partial\left(\rho_{\mathrm{g}} e_{\mathrm{g}}\right)}{\partial t}+\left(1-\phi_{\mathrm{s}}\right) \frac{\partial\left(u \rho_{\mathrm{g}} h_{\mathrm{g}}\right)}{\partial x}=h_{\mathrm{v}}\left(T_{\mathrm{s}}-T_{\mathrm{g}}\right)+a_{\mathrm{w}} h_{\mathrm{w}, \mathrm{conv}}\left(T_{\mathrm{w}}-T_{\mathrm{g}}\right)
$$

$$
\phi_{\mathrm{s}} \frac{\partial\left(\rho_{\mathrm{s}} e_{\mathrm{s}}\right)}{\partial t}=\frac{\partial}{\partial x}\left(k_{\mathrm{eff}} \frac{\partial T_{\mathrm{s}}}{\partial x}\right)+h_{\mathrm{v}, \text { rocks }}\left(T_{\mathrm{g}}-T_{\mathrm{s}}\right)-q_{\text {interface,rad }}+a_{\mathrm{w}} h_{\mathrm{w}, \text { cond-rad }}\left(T_{\mathrm{w}}-T_{\mathrm{s}}\right)
$$

$$
N u_{\text {rocks }}=\frac{h_{\text {rocks }} d_{\mathrm{p}}}{k_{\mathrm{g}}}=\frac{2.06}{1-\phi_{\mathrm{s}}} \operatorname{Re}_{0}^{0.425} \operatorname{Pr}_{\mathrm{g}}^{1 / 3} \quad\left[90 \lesssim R e_{0} \lesssim 4000, P r_{g} \approx 0.7\right]
$$

$$
\left(1-\phi_{\mathrm{epcm}}\right) \frac{\partial\left(\rho_{\mathrm{g}} e_{\mathrm{g}}\right)}{\partial t}+\left(1-\phi_{\mathrm{epcm}}\right) \frac{\partial\left(u \rho_{\mathrm{g}} h_{\mathrm{g}}\right)}{\partial x}=q_{\mathrm{enc}, \mathrm{g}}
$$

$$
\begin{aligned}
& \phi_{\mathrm{enc}} \frac{\partial\left(\rho_{\mathrm{enc}} e_{\mathrm{enc}}\right)}{\partial t}=-q_{\mathrm{enc}, \mathrm{g}}+q_{\mathrm{cond}, \mathrm{enc}}+q_{\mathrm{rad}, \mathrm{enc}}+q_{\mathrm{pcm}, \mathrm{enc}}+q_{\text {interface,rad }}+q_{\text {top,rad }}+ \\
& \frac{a_{\mathrm{w}} f_{\mathrm{cont}, \mathrm{w}} k_{\mathrm{enc}}}{\left(r_{\mathrm{tank}}-t_{\mathrm{enc}}\right) \ln \left(\frac{r_{\mathrm{tank}}}{r_{\mathrm{tank}}-t_{\mathrm{enc}}}\right)}\left(T_{\mathrm{w}}-T_{\mathrm{enc}}\right)
\end{aligned}
$$

$$
N u_{\text {enc }}=\frac{h_{\text {enc }} d_{\text {tubes }}}{k_{\mathrm{g}}}=0.51 C_{\text {row }} \operatorname{Re}_{\max }^{1 / 2} P r_{\mathrm{g}}^{0.37}\left(\frac{P r_{\mathrm{g}}}{P r_{\mathrm{s}}}\right)^{1 / 4} \quad\left[40<R e_{\max }<1000\right]
$$

$$
\frac{\partial\left(\rho_{\mathrm{pcm}} e_{\mathrm{pcm}}\right)}{\partial t}=\frac{1}{r} \frac{\partial}{\partial r}\left(k_{\mathrm{pcm}} r \frac{\partial T_{\mathrm{pcm}}}{\partial r}\right)-q_{\mathrm{pcm}, \mathrm{enc}}
$$

$$
\frac{\partial\left(\rho_{\mathrm{str}} e_{\mathrm{str}}\right)}{\partial t}=\frac{1}{r} \frac{\partial}{\partial r}\left(k_{\mathrm{str}} r \frac{\partial T_{\mathrm{str}}}{\partial r}\right)+\frac{\partial}{\partial x}\left(k_{\mathrm{str}} \frac{\partial T_{\mathrm{str}}}{\partial x}\right)+q_{\text {boundary }}
$$

$$
\phi_{g}(r)=\phi_{g, \text { bulk }}\left[1+C_{1} \exp \left(-C_{2} \frac{r_{\text {tank }}-r}{d_{p}}\right)\right]
$$


with temperature-dependent properties. ${ }^{[17]}$ Temperature-dependent properties of solid materials are also implemented. ${ }^{[6,13.17]}$ Thermal losses by convection and radiation are considered assuming a surroundings temperature of $20^{\circ} \mathrm{C}$ and a convective heat-transfer coefficient of $5 \mathrm{~W} / \mathrm{m}^{2} \mathrm{~K}$. The PISO and PRESTO ${ }^{[26]}$ methods were used to couple the velocity and pressure fields and to solve the pressure-correction equation. Convergence was considered to have been achieved when the mass, momentum, and turbulence residuals were below $10^{-5}$ and the energy residual was below $10^{-8}$.

\subsubsection{Sensible Heat Section}

For randomly packed spherical particles of uniform diameter, the void fraction in the bulk region ranges between $0.36-0.42$. ${ }^{27]}$ The packing structure is affected by the tank wall for a distance of approximately $5 d_{p}$. In this near-wall region, the void fraction distribution follows a damped oscillatory variation, from a value close to unity at the wall to a minimum of approximately 0.2 at a distance of about $d_{p} / 2$ from the wall. For a distance greater than about $5 d$ from the wall, the void fraction approaches the value in the bulk region. For packed beds of non-spherical and non-homogeneous particles, the variation of the void fraction in the radial direction is better described by an exponential decay affecting the packing structure for a distance of about $2-3 d_{p}{ }^{\text {[28] }}$ The near-wall void fraction variation leads to channeling, which is important if the tank-to-particle diameter ratio is lower than 25-30. ${ }^{[29,30]}$ Since the lab-scale storage is characterized by a diameter ratio of about 12.5 , the radial void-fraction distribution is included in the 2D model, ${ }^{[31]}$ see Eqn. (9), where $C_{1}$ $=1.2$ and $C_{2}=2.0 .{ }^{[32]}$ An effective thermal conductivity, ${ }^{[21,33]}$ implemented in Fluent through a user-defined function, was used to account for the conduction- and radiation-driven heat transfer in the packed bed.

\subsubsection{Latent Heat Section}

The effective heat-capacity method[34] was used to model the phase transition of the PCM. This method allows the phase transition to be modeled without the need for explicit tracking of the phase boundary by combining the latent heat of fusion with the specific heat. This so-called effective heat capacity was defined as a piecewise linear function of the temperature. The PCM and encapsulation were modeled as a single material with equivalent thermophysical properties. A sensitivity analysis was performed to ensure that the time step did not affect the phase transition. Radiation from the top plate to the topmost tube row was accounted for by adding a source term that was extracted from the 1D model.

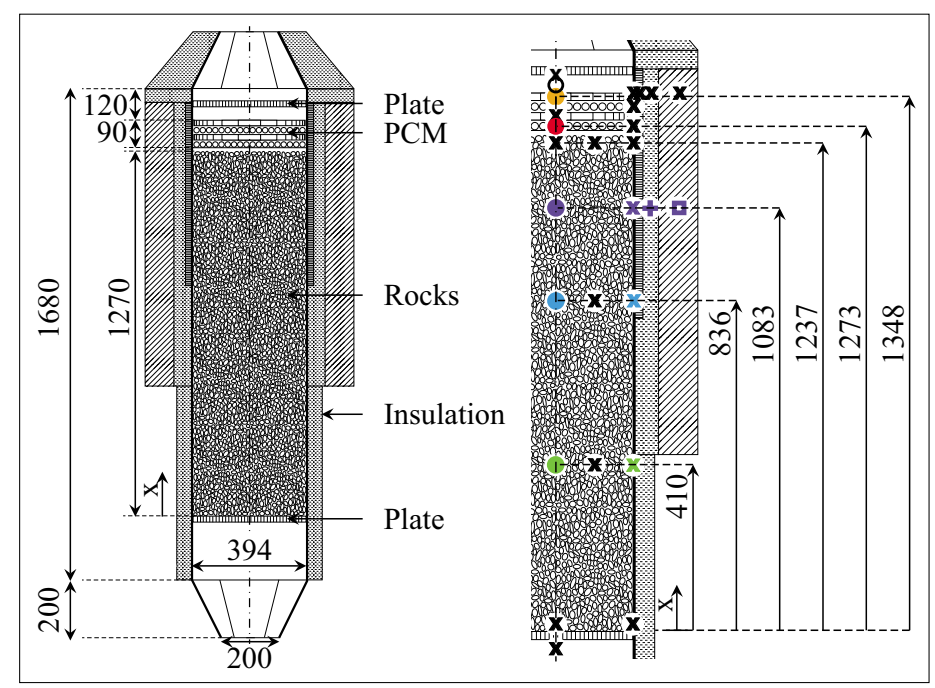

Fig. 1. Schematic of combined sensible/ latent heat TES and thermocouple locations (circles and crosses). All dimensions in $\mathrm{mm}$.

\section{Experimental Setup}

The combined sensible/latent heat labscale TES consists of encapsulated $\mathrm{AlSi}_{12}$ on top of a packed bed of rocks in an insulated cylindrical tank. A schematic with dimensions and the locations of the thermocouples is shown in Fig. 1. The inlet temperature of the air above the topmost tube row was measured by a shielded thermocouple. A radiation correction was applied to the measured temperature, see ref. [15]. The packed bed consisted of rocks with an average diameter of $32 \mathrm{~mm}$ and a total mass of $245 \mathrm{~kg}$. The average void fraction of the bed was measured to be 0.4. ${ }^{[13]} \mathrm{AlSi}_{12}$ was chosen as the PCM due to its melting temperature being suitable for AA-CAES and CSP applications as well as due to its high heat of fusion, high thermal conductivity, and comparatively low cost. ${ }^{[8]}$ The encapsulation was made of AISI 316 steel tubes with an inner diameter of $16 \mathrm{~mm}$ and a wall thickness of $1 \mathrm{~mm}$. Four rows of 17 tubes each were stacked at angles of $45^{\circ}$. The masses of the PCM and encapsulation were $9.27 \mathrm{~kg}$ and 13.17 $\mathrm{kg}$, respectively. Thermal conductivities, heat capacities, and densities of the PCM and the encapsulation are given in ref. [14]. The heat of fusion of the PCM is $466 \mathrm{~kJ} /$ $\mathrm{kg}$ with a melting range of $4 \mathrm{~K} .{ }^{[13]}$ The formation of an intermetallic layer between encapsulation and PCM was neglected, but is under investigation in a companion project. ${ }^{[9]}$ The tank was made of $3 \mathrm{~mm}$ thick stainless AISI 304 steel and was insulated with Microtherm ${ }^{\circledR}$, felt, and rockwool. The thicknesses of the insulation layers as well as the thermophysical properties of the tank and insulation materials are given in ref. [14]. Two perforated steel plates of 20 $\mathrm{mm}$ thickness were used for flow homogenization at the top and the bottom of the storage. The storage was charged with air at up to $595^{\circ} \mathrm{C}$ from the top and discharged with air at room temperature from the bot- tom. The total capacity of the combined storage is $42.4 \mathrm{kWh}_{\text {th }}$.

\section{Results}

Two experimental runs under identical conditions were performed to obtain the temperature measurements at all desired positions, as only 26 thermocouple ports could be used in each run. To check reproducibility, 9 of the 26 thermocouples were connected in both runs. For these thermocouples, it was found that the mean temperature differences between the runs did not exceed $8 \mathrm{~K}$ or $1.4 \%$. Figs 2, 3, and 4 show comparisons of the measured and simulated PCM, packed-bed, and tank-wall and insulation temperatures during one chargedischarge cycle with $\Delta t=3.25 \mathrm{~h}$, respectively. The symbols and colors correspond to those used in Fig. 1. The predictions by the $1 \mathrm{D}$ model are superior to those by the 2D model for the latent section. During discharging, the predictions of the packedbed temperatures by the $2 \mathrm{D}$ model are more accurate than those of the 1D model, however. Fig. 5 presents the temperature distribution at the end of charging. The 2D model results clearly show the substantial radial gradients caused by the small values of the tank-to-particle diameter ratio.

\section{Conclusions and Outlook}

Simulations with 1D and 2D models of a lab-scale combined sensible/latent heat storage were validated with experimental results. Radial gradients were significant because of the small tank-to-particle diameter ratios and were represented well by the $2 \mathrm{D}$ model. The $2 \mathrm{D}$ simulations were used to extract the bypass fraction that was employed to represent the unresolved radial gradients in the 1D model. For larger tank-to-particle diameter ratios, as encountered in industrial-scale storage units, the 

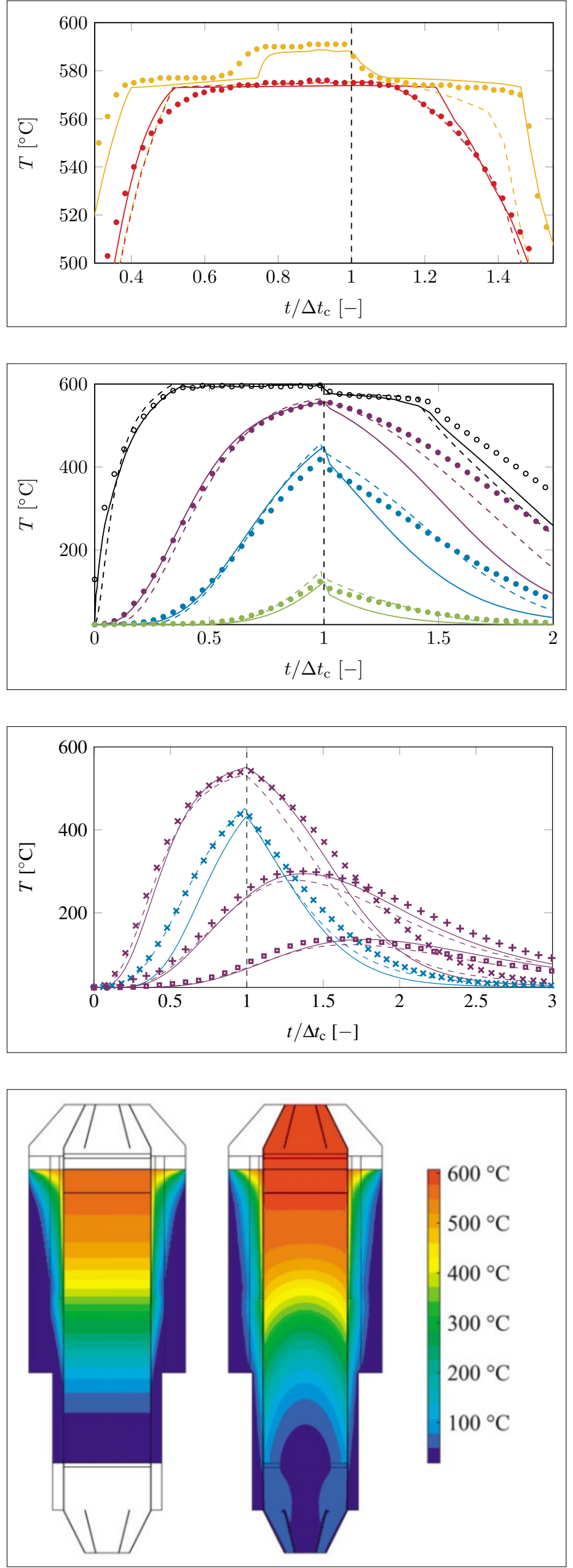

Fig. 2. Comparison of PCM temperatures. Circles represent experimental measurements and solid and dashed lines represent the simulated solid/molten phase temperatures from the $1 \mathrm{D}$ and 2D models, respectively.

Fig. 3. Comparison of packed-bed temperatures. Bullets represent experimental measurements and solid and dashed lines represent the simulated air temperatures from the $1 \mathrm{D}$ and $2 \mathrm{D}$ models, respectively.

Fig. 4. Comparison of tank wall and insulation temperatures. Markers represent experimental measurements and solid and dashed lines represent the simulated temperatures from the 1D and 2D models, respectively.

Fig. 5. Temperature distributions of the 1D (left) and 2D (right) models at the end of charging. The air temperature is shown in the storage itself whereas the solid temperature is shown in the storage walls and insulation. effect of radial gradients will decrease significantly and the validated 1D model can therefore be applied with confidence. Future work includes improved modeling of radiation effects in the $2 \mathrm{D}$ model and incorporation of correlations for the evolution of intermetallic layers between the PCM and the encapsulation. ${ }^{[9]}$

\section{Nomenclature \\ Latin characters}

a Surface area per unit volume $\left[\mathrm{m}^{2} / \mathrm{m}^{3}\right]$

c Heat capacity [J/kgK]

$d$ Diameter [m]

$e \quad$ Specific internal energy $\quad[\mathrm{J} / \mathrm{kg}]$

$f \quad$ Area fraction $[-]$

$h \quad$ Specific enthalpy $\quad[\mathrm{J} / \mathrm{kg}]$

Heat-transfer coefficient $\quad\left[\mathrm{W} / \mathrm{m}^{2} \mathrm{~K}\right]$

$h_{v} \quad$ Volumetric heat-transfer

coefficient

$\left[\mathrm{W} / \mathrm{m}^{3} \mathrm{~K}\right]$

$k \quad$ Thermal conductivity $\quad[\mathrm{W} / \mathrm{mK}]$

$m$ Mass [kg]

$N \quad$ Number of layers / units $\quad[-]$

$q \quad$ Volumetric heat flux $\quad\left[\mathrm{W} / \mathrm{m}^{3}\right]$

$r$ Radius [m]

$S_{\mathrm{t}} \quad$ Transverse pitch

between tubes $[\mathrm{m}]$

$T$ Temperature [K]

$t$ Time [s]

$u \quad$ Interstitial velocity [m/s]

$u_{0} \quad$ Superficial velocity $\quad[\mathrm{m} / \mathrm{s}]$

$V$ Volume $\left[\mathrm{m}^{3}\right]$

$x \quad$ Axial coordinate [m]

\section{Greek characters}

$\varepsilon \quad$ Emissivity $[-]$

$\rho \quad$ Density

$\mu \quad$ Dynamic viscosity

$\sigma \quad$ Stefan-Boltzmann constant $5.6704 \cdot 10^{-8}$

$\phi \quad$ Volume fraction

Dimensionless numbers

$\mathrm{Nu} \quad$ Nusselt number, $h d / k_{\text {a }}$

$\mathrm{Pr} \quad$ Prandtl number, $\mu \mathrm{c} / \mathrm{k}_{\mathrm{g}}$

$R_{0} \quad$ Superficial Reynolds number, $\rho_{\mathrm{g}} u_{0} d / \mu$

[-]

$R e_{\max }$ Reynolds number for tubes, $r_{\mathrm{g}} u_{\text {max }} d_{\text {tubes }} / \mathrm{m}$

\section{Subscripts}

0 Undisturbed flow

$\infty \quad$ Surroundings

c Charging

cond Conductive

cont Contact

conv Convective

d Discharging

eff Effective

enc Encapsulation

epcm Encapsulation and PCM

g Gas

max Maximum

p Particle

rad Radiative

s Solid

str Storage wall and insulation

$\mathrm{v} \quad$ Volumetric

w Wall 


\section{Acknowledgments}

Funding by the Swiss Commission for Technology and Innovation through the Swiss Competence Center for Energy Research for Heat and Electricity Storage, and by the European Union under the 7th Framework Program - Grant No. 312643 (SFERA-II) - is gratefully acknowledged.

Received: August 24, 2015

[1] F. Crotogino, 'Compressed air energy storage caverns to integrate fluctuating wind energy within transmission grids in Germany', in 'Underground Storage of $\mathrm{CO}_{2}$ and Energy', Ed J. S. Yoon, CRC Press, 2010, pp. 279-284.

[2] S. Zunft, C. Jakiel, M. Koller, C. Bullough, 'Adiabatic compressed air energy storage for the grid integration of wind power' Sixth International Workshop on Large-Scale Integration of Wind Power and Transmission Networks for Offshore Windfarms, 2006.

[3] G. Locatelli, E. Palerma, M. Mancini, Energy 2015, 83, 15.

[4] J. E. Pacheco, S. K. Showalter, W. J. Kolb, J. Sol. Energy Eng. 2002, 124, 153.

[5] M. Hänchen, S. Brückner, A. Steinfeld, Appl. Therm. Eng. 2011, 31, 1798.

[6] G. Zanganeh, A. Pedretti, S. Zavattoni, M Barbato, A. Steinfeld, Sol. Energy 2012, 86, 3084.
[7] G. Zanganeh, A. Pedretti, A. Haselbacher, A. Steinfeld, Appl. Energy 2015, 137, 812.

[8] M. M. Kenisarin, Renew. Sust. Energy Rev. 2010, 14, 955.

[9] D. Y. S. Perraudin, S. R. Binder, E. Rezaei, A. Ortona, S. Haussener, CHIMIA 2015, 69, 780.

[10] R. Ratzesberger, B. Beine, E. Hahne, VDI Berichte 1994, 1168, 467.

[11] E. Hahne, U. Taut, U. Gross, Solar World Congress 1991, 2, 1937.

[12] G. Zanganeh, M. Commerford, A. Haselbacher, A. Pedretti, A. Steinfeld, Appl. Therm. Eng. 2014, 70, 316

[13] G. Zanganeh, R. Khanna, C. Walser, A. Pedretti, A. Haselbacher, A. Steinfeld, Sol. Energy 2015 , 114,77

[14] L. Geissbühler, M. Kolman, G. Zanganeh, A. Haselbacher, A. Steinfeld, 'Analysis of industrial-scale high-temperature combined sensible/ latent thermal energy storage', in ASME-ATIUIT Conference on Thermal Energy Systems: Production, Storage Utilization and the Environment, Napoli, 2015.

[15] L. Geissbühler, M. Kolman, G. Zanganeh, A. Haselbacher, A. Steinfeld, Appl. Therm. Eng. 2015, submitted for publication.

[16] V. R. Voller, Numer. Heat Transfer B 1990, 17, 155

[17] F. P. Incropera, D. P. Dewitt, T. L. Bergman, A S. Lavince, 'Fundamentals of Heat and Mass Transfer', John Wiley \& Sons, Hoboken, NJ, 2007.
[18] A. S. Gupta, G. Thodos, AIChE J. 1963, 9, 751.

[19] J. Beek, Adv. Chem. Eng. 1962, 3, 203.

[20] K. Ofuchi, D. Kunii, Int. J. Heat Mass Transfer 1965, 8, 749 .

[21] D. Kunii, J. M. Smith, AIChE J. 1960, 6, 71.

[22] A. Zukauskas, 'Heat transfer from tubes in crossflow', in 'Advances in Heat Transfer', vol. 8, Eds J. P. Hartnett, T. F. Irvine, Elsevier, 1972, pp. 93-160.

[23] T. H. Shih, W. W. Liou, A. Shabbir, Z. Yang, J. Zhu, Comput. Fluids 1995, 24, 227.

[24] J. Tu, G. H. Yeoh, C. Liun, 'Computational Fluid Dynamics - A practical approach', ButterworthHeinemann, 2008.

[25] D. A. Nield, A. Bejan, 'Convection in porous media' 3rd ed., USA, Springer, 2006.

[26] ANSYS, FLUENT - Theory guide, 2013.

[27] A. E. Scheidegger, 'The Physics of Fluid Flow through Porous Media', 3rd ed., Toronto, University of Toronto Press, 1974

[28] VDI Heat Atlas, 2nd ed., Germany, Springer, 2010.

[29] D. E. Beasley, J. A. Clark, Int. J. Heat Mass Transfer 1984, 27, 1659.

[30] A. M. Ribeiro, P. Neto, C. Pinho, Int. Rev. Chem. Engin. 2010, 2, 40.

[31] M. L. Hunt, C. L. Tien, Chem. Eng. Sci. 1990 , 45,55 .

[32] D. Vortmeyer, J. Schuster, Chem. Eng. Sci. 1983, 38, 1691

[33] S. Yagi, D. Kunii, AIChE J. 1957, 3, 373.

[34] D. Poirier, M. Salcudean, J. Heat Transf. 1988, 10,562 